\title{
Special issue to commemorate the International Year of Chemistry 2011
}

\section{Foreword}

At the behest of the International Union of Pure and Applied Chemistry (IUPAC) and the United Nations Educational, Scientific, and Cultural Organization (UNESCO), the 63rd General Assembly of the United Nations at its meeting in December 2008 adopted a resolution proclaiming 2011 as the International Year of Chemistry (IYC-2011). The year 2011 coincides with the $100^{\text {th }}$ anniversary of the Nobel Prize in Chemistry awarded to Madame Marie Curie and the founding of the International Association of Chemical Societies. The objectives of IYC-2011 are to increase the public appreciation of chemistry in meeting world needs, to encourage interest in chemistry among young people, and to generate enthusiasm for the creative future of chemistry.' This year also marks the $150^{\text {th }}$ birth anniversary of Acharya P C Ray, a pioneering chemistry researcher and an inspiring teacher hailed as the 'Father of Indian Chemistry'. There has been a great deal of interest around the globe to celebrate the International Year of Chemistry, IYC-2011, in various ways. In India too, a number of Institutions at all levels have taken the initiative to convey the importance of Chemistry at all levels, particularly to young children through lectures, quiz competitions, demonstrations and interactive sessions.

A few months ago, the Editorial Board of the Journal of Chemical Sciences decided that the Journal will celebrate this great event by bringing out a Special Issue during the year. The Board also decided that a number of young and emerging investigators around the country could be invited to contribute articles for the Special Issue. It is very gratifying to note that the response has been overwhelmingly positive in spite of the short notice culminating in the publication of this last issue of the year as special IYC-2011 commemorative issue.

The articles in this Special Issue cover a broad spectrum of topics in several emerging areas of chemistry. We hope that the readers of this Special Issue will get a glimpse of how the chemical researchers in India are approaching the problems of the 21st Century.

The publication of this Special Issue would not have been possible without the timely cooperation from the authors and reviewers. We thank them all for their contributions. Thanks are also due to our Editorial staff for their help and assistance. 